\title{
Biocontrol potential of Streptomyces sp. CACIS-1.5CA against phytopathogenic fungi causing postharvest fruit diseases
}

\author{
Zahaed Evangelista-Martínez * (D), Erika Anahí Contreras-Leal, Luis Fernando Corona-Pedraza and \\ Élida Gastélum-Martínez
}

\begin{abstract}
Background: Fungi are one of the microorganisms that cause most damage to fruits worldwide, affecting their quality and consumption. Chemical controls with pesticides are used to diminish postharvest losses of fruits. However, biological control with microorganisms or natural compounds is an increasing alternative to protect fruits and vegetables. In this study, the antifungal effect of Streptomyces sp. CACIS-1.5CA on phytopathogenic fungi that cause postharvest tropical fruit rot was investigated.

Main body: Antagonistic activity was evaluated in vitro by the dual confrontation over fungal isolates obtained from grape, mango, tomato, habanero pepper, papaya, sweet orange, and banana. The results showed that antagonistic activity of the isolate CACIS-1.5CA was similar to the commercial strain Streptomyces lydicus WYEC 108 against the pathogenic fungi Colletotrichum sp., Alternaria sp., Aspergillus sp., Botrytis sp., Rhizoctonia sp., and Rhizopus sp. with percentages ranging from 30 to 63\%. The bioactive extract obtained from CACIS-1.5 showed a strong inhibition of fungal spore germination, with percentages ranging from 92 to $100 \%$. Morphological effects as irregular membrane border, deformation, shrinkage, and collapsed conidia were observed on the conidia. Molecularly, the biosynthetic clusters of genes for the polyketide synthase (PKS) type I, PKS type II, and NRPS were detected in the genome of Streptomyces sp. CACIS-1.5CA.

Conclusions: This study presented a novel Streptomyces strain as a natural alternative to the use of synthetic fungicides or other commercial products having antagonistic microorganisms that were used in the postharvest control of phytopathogenic fungi affecting fruits.
\end{abstract}

Keywords: Actinobacteria, Streptomyces, Biological control, Fungal phytopathogens, Antifungal, Antagonistic activity

\section{Background}

Postharvest losses of fresh fruits and vegetables refer to the damages that occur along the food supply chain due to pathogen infection, handling, storage, transportation, and processing, thereby resulting in the reduction in quality, quantity, and market value of horticultural perishables (Kadder 2005). The Food and Agriculture

\footnotetext{
* Correspondence: zevangelista@ciatej.mx

Center for Research and Assistance in Technology and Design of the State of Jalisco AC (CIATEJ), Southeast Unit, Tablaje Catastral 31264 km 5.5 Carretera Sierra Papacal-Chuburná Puerto, Parque Científico y Tecnológico de Yucatán, CP 97302 Mérida, Yucatán, Mexico
}

\section{Springer Open}

(c) The Author(s). 2020 Open Access This article is licensed under a Creative Commons Attribution 4.0 International License, which permits use, sharing, adaptation, distribution and reproduction in any medium or format, as long as you give appropriate credit to the original author(s) and the source, provide a link to the Creative Commons licence, and indicate if changes were made. The images or other third party material in this article are included in the article's Creative Commons licence, unless indicated otherwise in a credit line to the material. If material is not included in the article's Creative Commons licence and your intended use is not permitted by statutory regulation or exceeds the permitted use, you will need to obtain permission directly from the copyright holder. To view a copy of this licence, visit http://creativecommons.org/licenses/by/4.0/. tries, more than $40 \%$ of the food losses occurred at postharvest and processing levels (FAO 2011). Fruit decay caused by bacteria and fungi has important repercussions in nutrimental and physicochemical quality and more important changes in appearance, texture, odor, and flavor. Among fungal pathogens, the most outstanding were Colletotrichum, Alternaria, Aspergillus, Botrytis, Rhizoctonia, and Rhizopus (FAO 2011, and Shafiee-Jood and Cai 2016).

The application of synthetic fungicides to the fruits in their postharvest stage has been applied systematically in 
a large number of products, with the aim of reducing the incidence of pathogenic fungi and prolonging their shelf life. However, the indiscriminate use of these products has led to the emergence of pathogenic strains resistant to the products, in addition to causing serious damage to human health, animals, and the environment (Rodríguez et al. 2014). To reduce the impact by synthetic fungicides, the use of bioactive compounds of natural origin has been evaluated, such as extracts and vegetable essential oils, chitosan, and jasmonate, among others, as well as antagonistic micro-organisms; all of them are considered less harmful to humans and the environment (Tripathi and Dubey 2004; Reyes-Díaz et al. 2016). Sustainable agriculture has been highlighted as a strategy for the biological management of fruit diseases in the postharvest stage. This strategy was based on the growing demand for fruits and vegetables free of chemical pesticides (Di Francesco et al. 2016).

The use of antagonistic microorganisms or their metabolites is a natural alternative to the use of synthetic fungicides to control fruit rot during the postharvest stage. For the control of postharvest rot in citrus by Penicillium italicum and in grapes by Botrytis cinerea, the yeast Kloeckera apiculata was used, showing growth inhibition due to competition for nutrients (Long et al. 2005). In another study, endophytic microorganisms isolated from guarana seeds showed an antagonistic effect in vitro against anthracnose-causing C. gloeosporioides in guarana fruits (Silva et al. 2016). Pseudomonas fluorescens was observed to be effective in controlling green mold in citrus caused by Penicillium digitatum. The possible modes of action may include inhibiting spore germination and mycelial growth, competition for nutrient and space sites, and inducing disease resistance (Wang et al. 2018). VOCs produced by Bacillus velezensis (diacetyl and benzaldehyde) have been identified as promising compounds to apply in active packaging during the postharvest commercialization of fruits, in particular antifungal volatiles against $B$. cinerea in grapes (Calvo et al. 2020).

The importance of bacterium of the genus Streptomyces is widely recognized for their ability to produce antibiotics, antifungals, enzymes (chitinases, glucanases, proteinases), and other bioactive metabolites that inhibited the growth of plant pathogenic microorganisms and naturally safety of fruits and vegetables (Chen et al. 2018). There were commercial products comprised of Streptomyces species, such as Actinovate (Natural Industries, Inc.) and Mycostop * (Verdara Oy), both used for the control of foliar and root diseases of various crops (Yuan and Crawford 1995). On the other hand, secondary metabolites produced by Streptomyces have been evaluated to control gray mold ( $B$. cinerea) in tomato fruits, in particular a polyene macrolide was able to reduce the incidence of the disease (Kim et al. 2019).
The CACIS-1.16CA strain produced a yellow watersoluble metabolite that accumulated in culture medium and correlated with an inhibitory effect on fungal growth. This bacterium has shown antagonistic activity against the phytopathogenic fungi, Curvularia sp., Aspergillus niger, Helminthosporium sp., Fusarium sp., Alternaria sp., Phytophthora capsici, Colletotrichum sp., and Rhizoctonia sp., all isolated from diseased plants (Evangelista-Martínez 2014a).

In the present study, the antagonistic activity of Streptomyces sp. CACIS-1.5CA against pathogenic fungi that cause diseases in fruits at the postharvest stage was evaluated. In addition, the inhibition of conidial germination by means of a bioactive extract produced by the CACIS1.5CA strain was evaluated.

\section{Main text}

\section{Materials and methods}

Microorganisms and cultures

Pure culture from strain CACIS-1.5CA was obtained from the Germplasm Bank of Actinomycetes conserved at $-20^{\circ} \mathrm{C}$. Repeated streaking onto fresh International Streptomyces Project 2 (ISP2) media was used to reactivate the strain. Culture of Streptomyces lydicus strain WYEC 108 was maintained as above and was used as comparison for antagonism analysis. A general working inoculum (GI) of spores was prepared to obtain a turbid suspension of $10^{8} \mathrm{CFU} / \mathrm{ml}$.

\section{Isolation of phytopathogenic fungi}

All fruits with symptoms of fungal diseases were collected in local supermarkets. Tissues with symptoms of rot or disease were washed with distilled water, disinfected in $1 \% \mathrm{NaOCl}$ for $2 \mathrm{~min}$ and washed 3 times with sterile distilled water to remove any residual chlorine. These tissues were placed on sterile filter paper in a Petri dish and kept at $25^{\circ} \mathrm{C}$ in the dark to induce spore production (Krug 2004). The monosporic cultures of the fungi were obtained from harvesting the conidia of each of them to perform serial dilutions up to $10^{-7}$. A $1 / 10$ of each of these dilutions was distributed in Petri dishes with potato dextrose agar (PDA) and incubated for $24 \mathrm{~h}$. With the help of a stereoscopic microscope, individual germinating conidia were located, which were reseeded with the help of a sterile needle in Petri dishes with PDA medium. These strains were allowed to grow for 15 days. In the case of the Rhizoctonia fungus, the purification of the strain was carried out by the hyphal tip method as described by Leyronas et al. (2012). The fungi were identified, using a polyphasic approach by combining morphological characteristics and disease symptoms of infected fruits. For all cases, the isolates were verified to infect healthy fruits (Table 1). The conidial and mycelia suspensions were prepared from cultures with 12-14 
Table 1 List of postharvest fungal pathogens used in the study

\begin{tabular}{llll}
\hline Fungi & Host & Disease & Infective test \\
\hline Colletotrichum musae & Banana (Musa paradisiaca) & Anthracnosis \\
Alternaria sp. & Tomato (Solanum lycopersicum) & Black spot & + \\
Colletotrichum sp. M 2.1 & Habanero pepper (Capsicum chinense) & Anthracnosis \\
Colletotrichum sp. M 1.2 & Habanero pepper & Anthracnosis \\
C. gloeosporioides & Papaya (Carica papaya) & Anthracnosis \\
Botrytis sp. & Tomato & Gray mold & + \\
Aspergillus sp. & Sweet orange (Citrus sinensis) & Postharvest rot \\
Rhizopus sp. & Grapes (Vitis vinifera) & Soft rot & + \\
Rhizoctonia sp. & Mango (Mangifera indica) & Rot mango fruit & + \\
\hline
\end{tabular}

days of growth in plates with PDA. To obtain the fungal conidial suspension, $5 \mathrm{ml}$ of a $0.5 \%$ Tween 80 solution was added to each Petri dish with the culture and with the support of a Drigalsky loop. The suspension was filtered through several layers of cotton to discard mycelium from the fungus and then centrifuged at $6000 \mathrm{rpm}$ for $10 \mathrm{~min}$ at $25^{\circ} \mathrm{C}$. The conidial pellet was washed twice with sterile distilled water and suspension was adjusted to $1 \times 10^{5}$ spores $/ \mathrm{ml}$. The Rhizoctonia mycelial suspension was prepared from a 12-day growth culture in PDA medium. Five milliliters of sterile distilled water was added to the Petri dish and the mycelium was removed from the agar using the Drigalsky loop. This suspension was centrifuged and washed as previously mentioned. The suspension with the mycelium was adjusted to a turbidity of approximately 0.5 of the McFarland scale.

\section{Evaluation of antagonistic activity against phytopathogenic fungi}

Evaluation of the antagonistic activity of the CACIS1.5CA strain on the growth of phytopathogenic fungi was carried out by dual confrontation in a Petri dish using ISP2 agar (Bredholdt et al. 2007). From a culture of Streptomyces of 15 days of growth, an inoculum was taken from the spores with a toothpick which was dispersed in an area of approximately $7 \times 14 \mathrm{~mm}$, located $1.5 \mathrm{~cm}$ from the edge of the Petri dish. Later, at the opposite end of the plate, a 6-mm-diameter agar disk covered with active fungal mycelium for 10-12 days of growth was deposited and kept in incubator at $29^{\circ} \mathrm{C}$. Plates inoculated only with the fungus were used as growth control. The growth of each species of fungi was recorded when the mycelium grew near the opposite edge in the control Petri dish. All experiments were performed in triplicate. The percentage of inhibition (PI) was determined according to the formula: PI $(\%)=(F R$ - AR)/FR $\times 100$, where FR represents the radial growth of the fungus (millimeters) of a control culture and AR represents the radial growth (millimeters) in the direction of the actinobacteria (Yuan and Crawford 1995).
For this study, the Streptomyces lydicus strain WYEC 108 was chosen as the reference strain.

\section{Preparation of the bioactive extract}

The metabolites that spread to the culture medium were obtained based on the procedure described by CórdovaDávalos et al. (2018). The production consisted of distributing a suspension of spores in 10 Petri dishes with ISP2 agar medium at the edge of the Petri dish, leaving a square space without the bacteria of approximately 3 $\mathrm{cm}^{2}$ in the center of the plates. The inoculated plates were kept in an incubator for 14 days at $29^{\circ} \mathrm{C}$. Subsequently, with a stainless-steel spatula the quadrant was separated and macerated and mixed with $150 \mathrm{ml}$ of absolute methanol. The mixture was refrigerated for $24 \mathrm{~h}$ at $4{ }^{\circ} \mathrm{C}$. The methanol was evaporated by a Buchi R-100 rotary evaporator at $60^{\circ} \mathrm{C}$ and the obtained precipitate was dissolved with $5 \mathrm{ml}$ of methanol to have a concentration of $258 \mathrm{mg} / \mathrm{ml}$ of the bioactive extract (BE).

\section{Antifungal activity of BE on conidial germination}

The conidial germination assay was implemented on 96well micro plates, wherein $50 \mu \mathrm{l}$ of the BE (stock at 258 $\mathrm{mg} / \mathrm{ml}$ in methanol) was deposited per well under an air cabinet, and open the lid for $5 \mathrm{~min}$ for evaporation of methanol. After that, $200 \mu \mathrm{l}$ of potato dextrose broth (PDB) was added and mixed to dissolve the precipitated BE. Finally, $5 \mu \mathrm{l}$ of a conidia suspension $\left(1 \times 10^{6} \mathrm{cell} / \mathrm{ml}\right)$ was mixed and incubated. The same procedure was carried out to the control assay by adding $50 \mu \mathrm{l}$ of methanol. Chemical control with carbendazim was also implemented. Microplates were maintained at $29^{\circ} \mathrm{C}$ in the dark. Effect on conidia germination was registered at 6 and $22 \mathrm{~h}$ after the treatments application. Conidia germination was observed by optical microscopy (magnification $=\times 40$ lens). For each treatment, one hundred conidia were examined, and the extent of spore germination was assessed by looking for germ tube emergence. The percentage of inhibition of conidial germination (PIG) was then calculated, where PIG $=\left(\mathrm{n}^{\circ}\right.$ control 
conidia $-\mathrm{n}^{\mathrm{o}}$ treatment conidia $/ \mathrm{n}^{\mathrm{o}}$ control conidia) $\times 100$, wherein $n^{\circ}$ control conidia $=$ number of conidia of control treatment and $\mathrm{n}^{\circ}$ control treatment $=$ number of $\mathrm{co}^{-}$ nidia of treatment (Catão et al. 2013).

\section{Molecular identification}

The identity of CACIS-1.5CA strain was determined based on partial length 16S rRNA gene sequence analysis. The genomic DNA used as a template for PCR was prepared from $100 \mu \mathrm{l}$ of a spore suspension using the Puregene Yeast/Bact Kit B (QIAGEN). The DNA purification protocol and PCR conditions were implemented as stated by Evangelista-Martínez (2014a). The complete 16S rRNA fragment was prepared by PCR amplification, using Platinum Taq DNA polymerase (Invitrogen) and oligonucleotides fD1 (5' CCGAATTCGTCGACAACA GAGTTT GATCCTGGCTCAG 3') and rD1 (5' CCCGGGATCCAA GCTTAAGGAGGTGATCCAGCC 3') (Weisburg et al. 1991). The amplified fragment was directly verified by nucleotide sequence determination of both strands at LANGEBIO (National Laboratory of Genomics for Biodiversity, CINVESTAV Irapuato, Mexico). Sequences were assembled and trimmed using CLC Main Workbench 6 (CLC Bio). The sequence analyzed for homology, using the Blastn Suite program and homologs $16 \mathrm{~S}$ rDNA gene sequences, were retrieved from the non-redundant GeneBank database (http:// blast.ncbi.nlm.nih.gov/). Phylogenetic analysis was carried out at Phylogeny.fr (http://www.phylogeny.fr). The selected sequences were aligned with MUSCLE (v3.7) configured for highest accuracy. After alignment, ambiguous were removed with Gblocks (v 0.91b). The phylogenetic tree was reconstructed, using the BioNJ program. The K2P substitution model was selected for the analysis. The confidence of the grouping was verified by bootstrap analysis (1000 replications). Partial sequence of $16 \mathrm{~S}$ rDNA gene of Streptomyces sp. strain CACIS-1.5CA was deposited in GenBank database under accession number MT322980.

\section{Screening for antibiotic biosynthetic genetic clusters}

PCR screening for the biosynthetic genes involved in the production of antimicrobial molecules by Streptomyces sp. CACIS-1.5CA was based on amplifications with specific primers. Polyketide synthase (PKS) type I gene fragments were amplified using the following degenerate

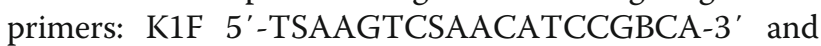
M6R 5'-CGCAGGTTSCSG TACCAGTA-3'. Nonribosomal peptide synthetase (NRPS) genetic fragments were amplified using the following degenerate primers: A3F 5'-GCSTACSYSATSTACACSTCSGG-3' and A7R 5'-SASGTCVCCSGTSCGGTAS-3' (Ayuso-Sacido and Genilloud 2005). Gene fragments of PKS type II gene were amplified using the degenerate primers $\mathrm{KS} \alpha 5^{\prime}$ -
TSGRCTACRTCAACGGSCACGG-3' and KS $\beta$ 5'TACSAGTCSWTCGCCTGGTTC-3' (González et al. 2005). Each reaction mixture ( $25 \mu \mathrm{l}$ final volume) consisted of $50 \mathrm{ng}$ of DNA template, $1 \mathrm{X}$ colorless GoTaq Flexi buffer, $2 \mathrm{mM} \mathrm{MgCl} 2,0.2 \mathrm{mM}$ of each dNTP (Invitrogen), $0.4 \mu \mathrm{M}$ of each primer, 1.25 U GoTaq Hot Start polymerase (Promega), and 10\% dimethyl sulfoxide (DMSO). The PCR amplification program was as previously stated (Ayuso-Sacido and Genilloud 2005). All amplification products were visualized on $1.5 \%(\mathrm{w} / \mathrm{v})$ agarose gels prepared in 1X Tris-Borate-EDTA (TBE) buffer (Invitrogen) and stained with ethidium bromide.

\section{Characterization of the strain CACIS-1.5CA}

Phenotypic characterization of the CACIS-1.5CA isolate morphological and biochemical characterization of the bioactive isolate was assessed according to Shirling and Gottlieb (1966) with slight modifications. For growth characterization, $2 \mu \mathrm{l}$ of GI were inoculated in 24-well culture plates containing different complex substrates, such as International Streptomyces Project medium 2 and 9 (ISP2 and 9), nutrient agar (NA), Simmons citrate agar (SCA), Oatmeal agar (OA), iron agar (IA), and PDA to evaluate the growth response on the diverse culture media. Carbon source assimilation was maintained with $1 \%(\mathrm{w} / \mathrm{v})$ D-glucose, D-xylose, D-arabinose, D-raffinose, D-cellobiose, D-fructose, L-raffinose, L-xylose, D-mannose, Mannitol, Myoinositol, and glycerol. Susceptibility or resistance to antimicrobials was studied by the disk diffusion method. Briefly, $0.1 \mathrm{ml}$ of CACIS-1.5CA spore suspension was evenly distributed onto Petri plates containing ISP 2 media as triplicate. Once the solution was absorbed, an antibiotic multidisc for Gram-positive bacteria II (Bio-Rad ${ }^{\circ}$, Hercule, CA, USA) was placed on the media's surface and was kept at $29 \pm 2{ }^{\circ} \mathrm{C}$ for 15 days. For all the tests, the differentiation steps, which included growth of mycelia substrate and spore production, were observed after a 14-day incubation period at $29^{\circ} \mathrm{C}$.

\section{Scanning electron microscopy of isolate, CACIS-1.5CA}

An agar block of $14 \times 14 \mathrm{~mm}$ with an active culture of CACIS-1.5CA from ISP2 media maintained at $29^{\circ} \mathrm{C} / 14$ $\mathrm{d}$ was placed into $2 \%$ glutaraldehyde in $0.2 \mathrm{M}$ phosphate buffer (PBS, pH 7.2), and left $48 \mathrm{~h}\left(24 \mathrm{~h}\right.$ at $25^{\circ} \mathrm{C}$ and $24 \mathrm{~h}$ at $4{ }^{\circ} \mathrm{C}$ ). The next day, the agar pieces were washed in 3 30-min changes of PBS buffer, followed by a 60 -min change in $30 \%$ ethanol, a 60 -min change in $50 \%$ ethanol, and a 60 -min change in $70 \%$ ethanol. The samples were analyzed with an electronic microscope EVO-50 (Carl Zeiss) at the Science Faculty from Autonomous University of Querétaro, México. 


\section{Data analysis}

The antagonism activity was expressed as means \pm standard deviation (SD). The means were compared using an analysis of variance (ANOVA one-way), followed by the Fisher test $(P=0.05)$. The statistical analyses were performed with the MiniTab v18 program (Minitab, LLC).

\section{Results and discussion \\ Morphological, biochemical, and physiological characterization of CACIS-1.5CA isolate}

The isolate CACIS-1.5CA was selected considering a previous study, wherein it showed its antagonism over fungal phytopathogens from genera Fusarium, Curvularia, Helminthosporium, and Aspergillus niger. Additionally, the strain was partially characterized (Evangelista-Martínez, 2014a). Morphologically, the colonies of the CACIS-1.5CA displayed orange-red substrate mycelia, white to cream aerial mycelia, and a white spore mass. In addition, some biochemical and physiological features were observed (data not shown). The sporulation morphology of the aerial hyphae was flexous with a rectiflexibiles spore chains type (Fig. 1) (Li et al. 2016).

\section{Molecular characterization}

The analysis of the partial 16S rRNA gene sequence (1462 bp) from the CACIS-1.5CA revealed a high similarity (98\%) with some Streptomyces sequences previously deposited in the GenBank. Considering its phenotypic features and the close relation to other Streptomyces species confirmed that the CACIS-1.5CA isolate belonged to the Streptomyces genus. The phylogenetic tree based on the neighbor-joining method showed that the CACIS-1.5CA strain was related to some Streptomyces species that were able to produce antimicrobial

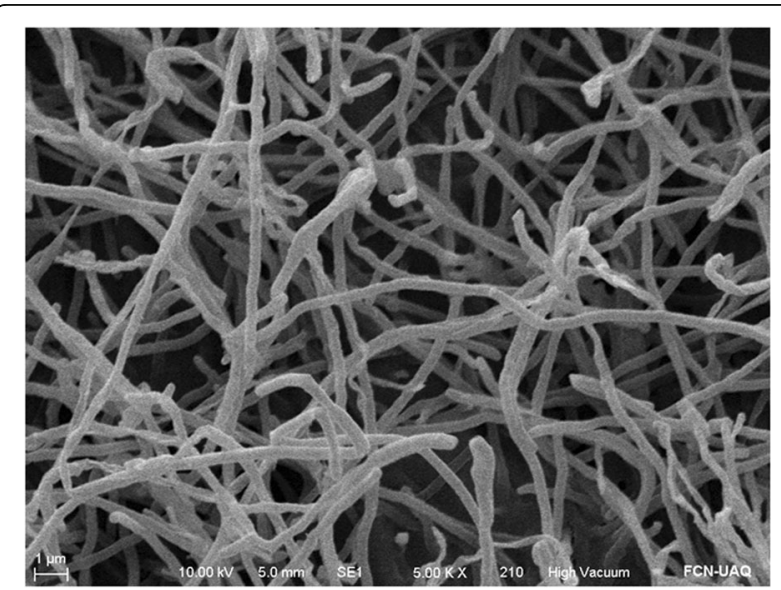

Fig. 1 Scanning electron micrograph showing spore morphology of Streptonyces sp. CACIS-1.5CA metabolites, e.g., S. alboflavus, S. variegatus, S. flavofungini and S. fulvissimus (Fig. 2). S. alboflavus produces volatile organic compounds with strong inhibitory activity of mycelial growth, sporulation, and conidial germination over Aspergillus flavus (Yang et al. 2019). S. variegatus (emended as Streptomyces flavovariabilis) produced alpha-hydroxyketopentaenes, an antibiotic active against gram-positive bacteria, yeasts, and fungi belonging to Penicillium species (Javoreková et al. 2019). S. flavofungini produced flavofungin, a macrolide antifungal antibiotic (Bognár et al. 1972), and S. fulvissimus produced valinomycin, a naturally occurring cyclodepsipeptide with a wide range of bioactivity (Zhang et al. 2020).

\section{Detection of biosynthetic gene clusters of secondary metabolites}

The biosynthetic clusters of genes for the PKS type I, PKS type II, and NRPS in the genome of Streptomyces sp. CACIS-1.5CA were detected by PCR. The amplified fragments corresponded to $\sim 1400 \mathrm{bp}$ for PKS-I, $1600 \mathrm{bp}$ for PKS-II, and to $\sim 700 \mathrm{bp}$ for NRPS. The members of Streptomyces species were a widely recognized group of antibiotic producers, with genomes containing more than 20 biosynthetic gene clusters for secondary metabolites, representing 5\% of their genome (Challis and Hopwood, 2003). These results indicated a potential for the strain as a producer of compounds with antifungal activity.

\section{Antagonistic activity of Streptomyces sp. CACIS-1.5CA}

The antagonistic activities of Streptomyces sp. CACIS-1.5CA against postharvest fungal phytopathogens were given in Table 2. It was shown that the PI was over fungal growth, wherein significantly differences were observed $(P<0.05)$. The bacterial-fungal confrontation assays revealed that CACIS-1.5CA inhibited the fungal mycelium at least by $30 \%$; the highest inhibitory activity on C. musae (62.73\%) and Alternaria sp. (53.2\%) was obtained. Similar PI results with $S$. lydicus WYEC 108 were obtained $(P<0.05)$. As above, WYEC 108 strain inhibited the mycelial growth of $C$. musae (>60\%) and maintained inhibitory growth activity in the range of 43 to $47 \%$, except for Rhizopus sp. and Rhizoctonia sp. fungi with values were below $30 \%$. In general, nonsignificant statistical differences were observed for PI between Streptomyces sp. CACIS-1.5CA and S. lydicus WYEC $108(P>0.5)$. However, it was noticed that CACIS$1.5 \mathrm{CA}$ showed superior antagonisms against Alternaria sp. and Rhizoctonia sp. pathogens from tomato and mango fruits, respectively, than S. lydicus (Fig. 3). In a previous work, it was shown that strain CACIS-1.5CA inhibited the mycelium growth of Curvularia sp. by $44 \%$, Helminthosporium sp. by $37 \%$, A niger by $40 \%$, and Fusarium sp. by $42 \%$ (Evangelista-Martínez 2014a). The above results strongly 


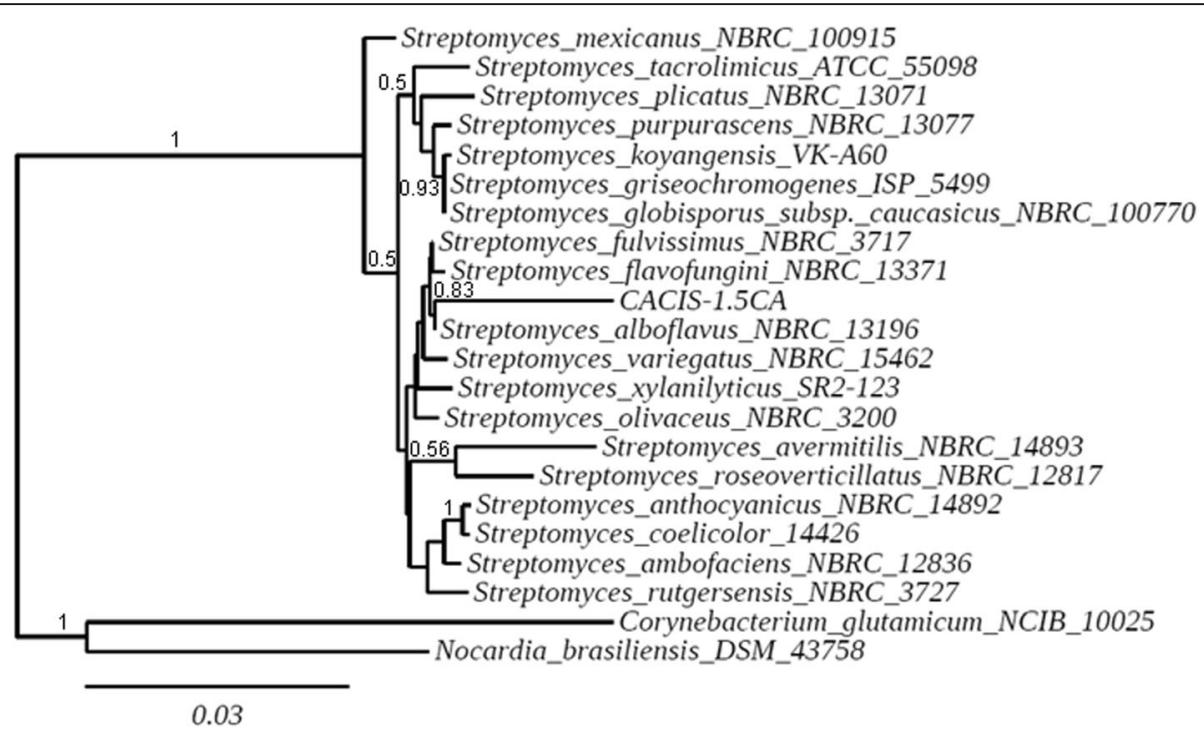

Fig. 2 Phylogenetic relationship among Streptomyces sp. CACIS-1.5CA and other Streptomyces species. The numbers at the nodes representing percentage values that indicated bootstrap support levels ( $n=1000$ resamplings). The scale bar represented 0.03 nucleotide substitutions per site

suggested that CACIS-1.5CA could be considered a potential control agent to prevent and/or reduce plant diseases caused by fungal pathogens. Many researchers have studied the potential of several Streptomyces species to control plant pathogens. Streptomyces sp. strain CACIA-1.46HGO demonstrated the production of secondary metabolites and extracellular enzymes that possibly acted in combination to inhibit the mycelial growth of some fungal pathogens (Evangelista-Martínez 2014b). Volatile substances from Streptomyces globisporus JK-1 exerted antifungal activity over spore germination and mycelial growth against Penicillium italicum in vitro and in planta (Li et al. 2010). Also, Streptomyces alboflavus strain TD-1 produced volatiles that inhibited in vitro the storage fungi Fusarium moniliforme, Aspergillus flavus, A. ochraceus, A. niger, and Penicillium citrinum (Wang et al. 2013). An indigenous soil isolate, Streptomyces violascens MT7 was assessed for its biocontrol potential under both in vitro and in vivo against various pathogenic postharvest fungi of citrus and papaya, Colletotrichum gloeosporioides, and A. niger (Choudhary et al. 2015). Inhibition of mycelial growth of Botrytis cinerea, a major causal fungus of postharvest root rot of ginseng and strawberry gray mold disease, was induced by Streptomyces sp. BS062 (Kim et al. 2015).

\section{Inhibition of spore germination by the bioactive extract}

A preliminary study to evaluate the effects of the crude extract of Streptomyces sp. CACIS-1.5CA on conidial germination of some pathogenic fungi was implemented. Results of PIG were based on a final concentration of $12.9 \mathrm{mg} / \mathrm{ml}$ for BE (in gray). As controls for germ growth of conidia, distillated water and carbendazim as inhibitory germ control at final concentration of $3.3 \mu \mathrm{g} / \mathrm{ml}$ (in black) were used (Fig. 4). The results showed that spore germination of all the fungal conidia were inhibited by the $\mathrm{BE}(P<0.05)$.

Table 2 Antagonism activity of Streptomyces sp. strain CACIS-1.5CA against fungal phytopathogens

\begin{tabular}{lll}
\hline Pathogen & Streptomyces lydicus WYEC 108 $^{\text {* }^{\mathrm{N}}}$ & Streptomyces sp., CACIS-1.5CA $^{{ }^{*}}$ \\
\hline Colletotrichum musae & $60.71 \pm 3.55^{\mathrm{a}}$ & $62.73 \pm 1.84^{\mathrm{a}}$ \\
C. gloeosporioides & $47.12 \pm 2.58^{\mathrm{b}}$ & $42.09 \pm 1.91^{\mathrm{c}}$ \\
Colletotrichum sp. M 2.1 & $46.75 \pm 0.95^{\mathrm{b}, \mathrm{c}}$ & $45.21 \pm 2.71^{\mathrm{c}}$ \\
Colletotrichum sp. M 1.2 & $44.49 \pm 0.16^{\mathrm{b}, \mathrm{c}}$ & $42.21 \pm 0.49^{\mathrm{c}}$ \\
Alternaria sp. & $43.81 \pm 1.68^{\mathrm{b}, \mathrm{c}}$ & $53.20 \pm 1.37^{\mathrm{b}}$ \\
Botrytis sp. & $46.44 \pm 0.59^{\mathrm{b}, \mathrm{c}}$ & $43.59 \pm 0.53^{\mathrm{c}}$ \\
Aspergillus sp. & $44.32 \pm 0.87^{\mathrm{b}, \mathrm{c}}$ & $39.36 \pm 1.0^{c}$ \\
Rhizopus sp. & $27.44 \pm 0.42^{\mathrm{d}}$ & $31.56 \pm 1.81^{\mathrm{d}}$ \\
Rhizoctonia sp. & $16.9 \pm 4.12^{\mathrm{e}}$ & $30.75 \pm 1.08^{\mathrm{d}}$
\end{tabular}

${ }^{\bar{*}}$ Means with different letter(s) are significantly different $(p<0.05)$ 


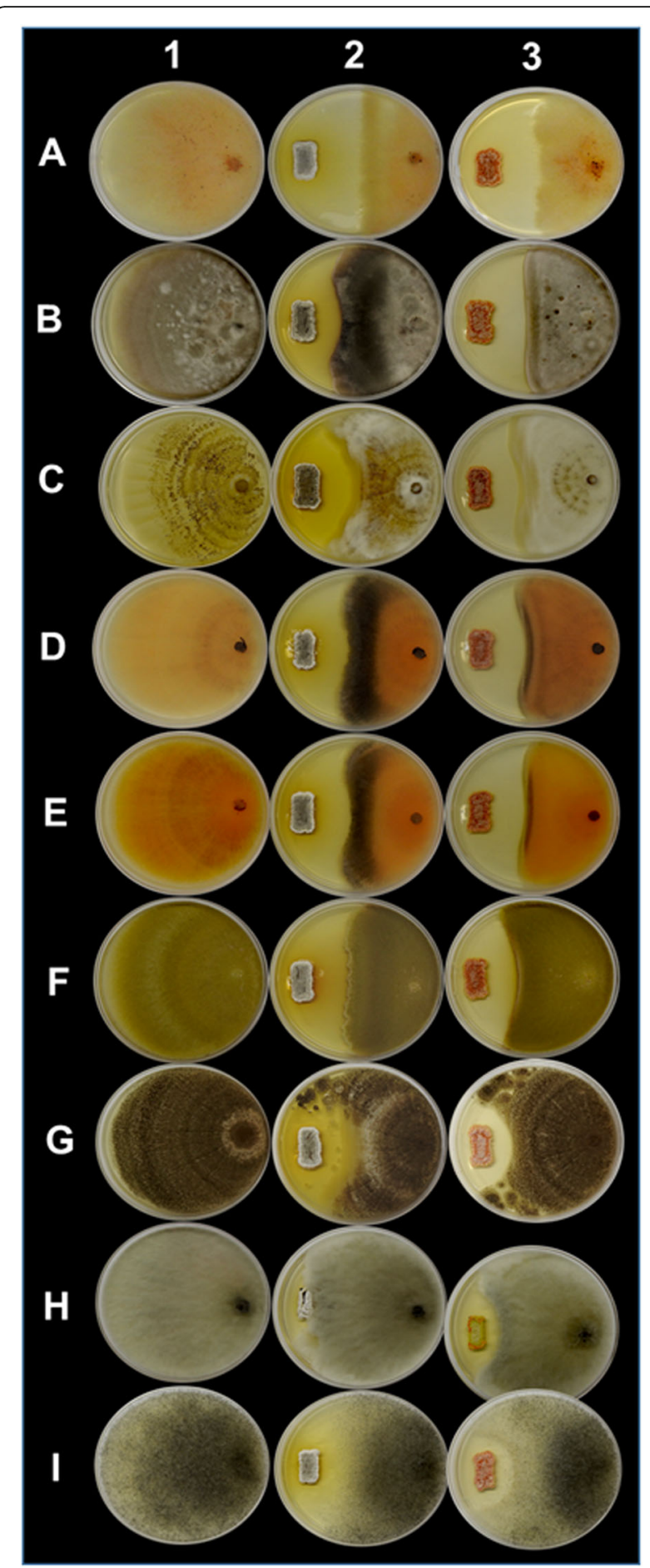

Fig. 3 Antagonist assay by dual confrontation. (A) Colletotrichum musae, (B) Alternaria sp., (C) Colletotrichum sp. M2.1, (D) Colletotrichum sp. M1.2, (E) C. gloeosporioides, (F) Botrytis sp., (G) Aspergillus sp., (H) Rhizoctonia sp., and (I) Rhizopus sp. (1) Control growth, (2) S. lydicus WYEC 108 antagonism, and (3) Streptomyces sp. CACIS-1.5CA antagonism
The concentration used was effective against conidia germination; the minimum PIG was $92 \%$ for Alternaria sp. In contrast, carbendazim, at the concentration used, does not affect the germination process for C. gloeosporioides, Alternaria sp., and Rhizopus sp. For Colletotrichum sp. M1.2, the PIG was 50\%, and solely for Aspergillus sp., C. musae, and for Botrytis sp. PIG was superior to $70 \%$. Cell-free culture filtrates from Streptomyces katrae strain NB 20 showed significant inhibitory effects on mycelial growth and conidial germination of C. musae; for conidial germination, the inhibitory effects were $97.7 \pm 0.9 \%$ and $95.0 \pm 0.6 \%$ (Shu et al. 2017). Recently, a secondary metabolite purified from Streptomyces rectiviolaceus DY46 reduced the incidence of gray mold of tomato fruits by $80 \%$ in tomatoes treated with the cell extract compared with the control tomatoes (Kim et al. 2019).

The effect of BE on conidial morphology of $C$. musae was followed at 6 and $22 \mathrm{~h}$ after the exposition to the extract and observed by optical microscopy (Fig. 5). It was observed in control germination experiment, a germ tube formation in at least $70 \%$ of conidia, $6 \mathrm{~h}$ after the initiation of incubation, increased to $100 \%$ after $22 \mathrm{~h}$ (Fig. 5a, c). In contrast, no conidial germination was detected in the first $6 \mathrm{~h}$ of incubation with an extremely low germination rate after $22 \mathrm{~h}$ (Fig. 5b, d). It was observed that morphological changes in the majority of conidia treated with the $\mathrm{BE}$, including irregular membrane border, deformation, and shrinkage, collapsed compared to conidia in the control (red arrows); some conidia appeared bigger than control (green arrows). These bigger conidia possibly survived in the $\mathrm{BE}$ treatment since it was observed growing hyphae with chlamydosporelike cells at $22 \mathrm{~h}$ post-treatment (black arrows). The antibiotics produced by Streptomyces have been proposed as alternative fungicides to replace synthetic chemical compounds and controlling fungal diseases. It has been reported that Streptomyces violaceusniger YCED9 produced nigericin, a guanidylfungin A-like compound, and geldanamycin that inhibit Pythium, Fusarium, and Phytophthora sp. (Trejo-Estrada et al. 1998). Soil samples previously treated with a culture filtrate that enriched with azalomycin produced by $S$. malaysiensis decreased fungal growth of Fusarium oxysporum, Rhizoctonia solani, Cladosporium cladosporioides, Fusarium chlamydosporum, Colletotrichum gloeosporioides, Alternaria mali, and Pestalotia spp. (Cheng et al. 2010). Polyketides reveromycins A and B from Streptomyces sp. 3-10 demonstrated a high antifungal activity against Botrytis cinerea, Mucor hiemails, Rhizopus stolonifer, and Sclerotinia sclerotiorum and suppressed strawberry fruit rot caused by the 


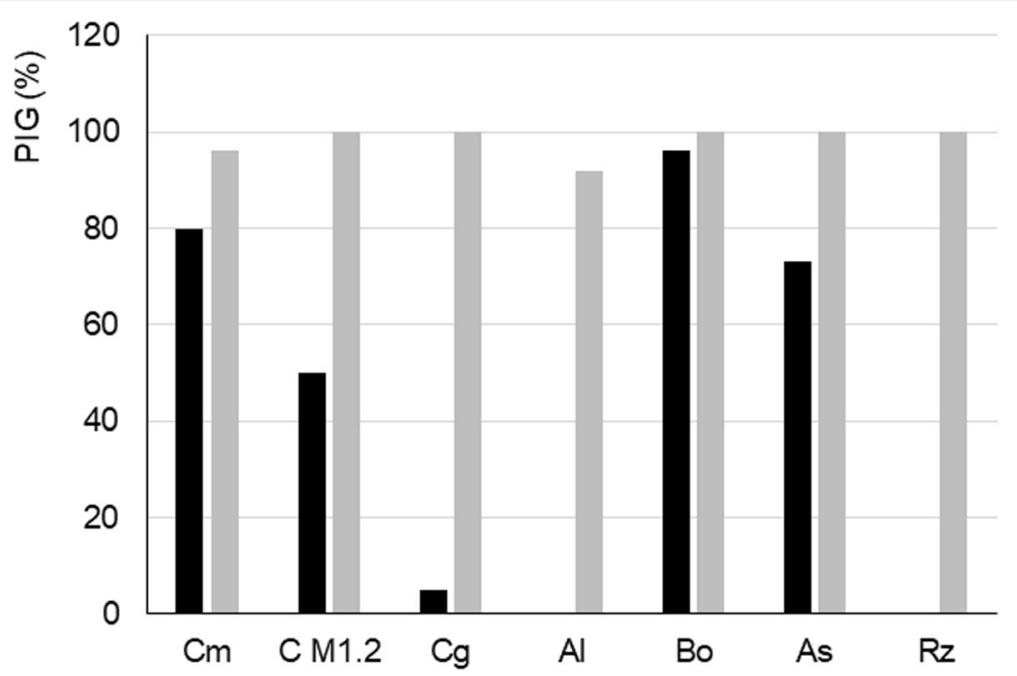

Fig. 4 Effects of BE on percentage of inhibition germination (PIG) of conidia. The germination was registered after $22 \mathrm{~h}$ of extract application. $\mathrm{Cm}$, C. musae; C M1.2, Colletotrichum sp., M1.2; Cg, C. gloeosporioides; Al, Alternaria sp.; Bo, Botrytis sp.; As, Aspergillus sp.; Rz, Rhizopus sp.

abovementioned four pathogens (Lyu et al. 2017). Furthermore, the crude extract of Streptomyces sp. CB-75 significantly inhibited spore germination of $C$. musae and C. gloeosporioides, wherein the conidia's showed deformation, shrinkage, collapse, and tortuosity morphology (Chen et al. 2018). The consequences of incorrect handling and storage conditions of fruits and vegetables after their harvest, represented global losses during the year estimated to be $40-50 \%$ for root crops, fruits, and vegetables (Sawicka 2019). Several fungal and bacterial microorganisms caused several principal postharvest decays of fruits. Chemical treatment with fungicide has been used as the first line of defense to control fungal diseases. However, an increased interest to use biological methods to postharvest control of fruit decay represented a public concern for food safety.

\section{Conclusion}

Streptomyces sp. CACIS-1.5CA has a wide antagonistic and inhibitory capacity for the inhibition of phytopathogenic fungi that affected fruits in the postharvest stage,
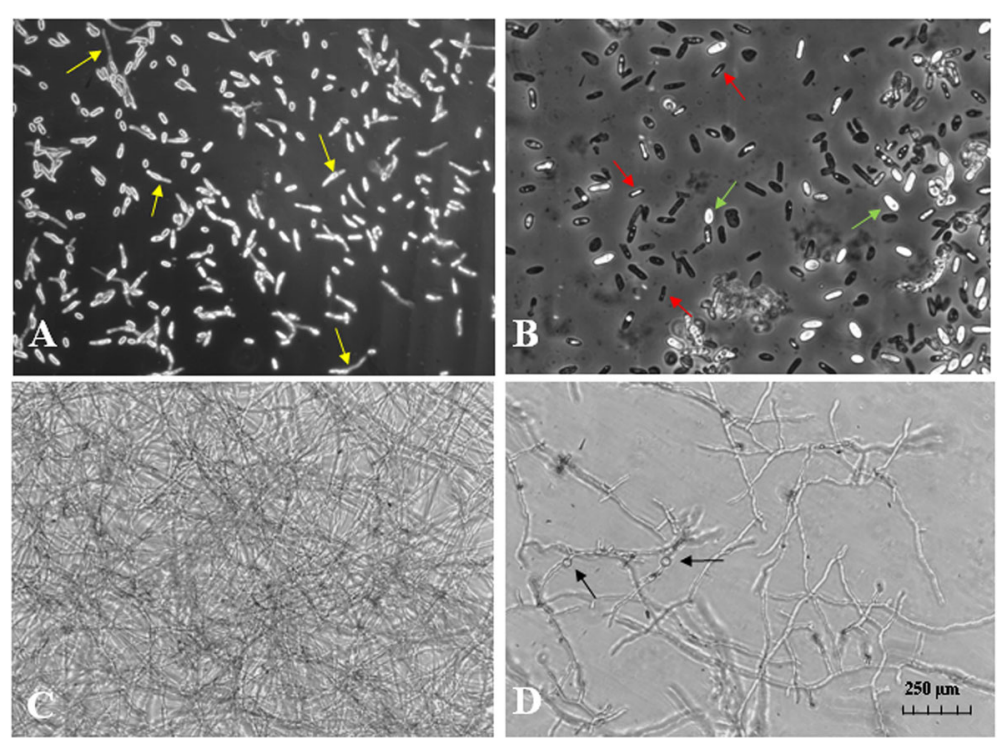

Fig. 5 Morphological effects of BE on germination of Colletotrichum musae conidia. a, c Conidial germination of control assay after 6 and $22 \mathrm{~h}$, respectively; yellow arrows showed germ tube formation. $\mathbf{b}$, $\mathbf{d}$ Conidial germination of BE assay after 6 and $22 \mathrm{~h}$, respectively; red arrows showed damages in conidia, green arrows showed unaffected conidia by BE treatment, and black arrows showed chlamydospore-like cells 
including Colletotrichum, Alternaria, Aspergillus, Botritys, Rhizoctonia, and Rhizopus. The metabolites produced by this Streptomyces represented a viable and natural alternative for the control of a wide range of phytopathogenic fungi.

\section{Abbreviations}

ANOVA: Analysis of variance; BE: Bioactive extract; CFU: Colony-forming unit; EDTA: Ethylenediaminetetraacetic acid; FAO: Food and Agriculture Organization; Gl: General inoculums; NaOCl: Sodium hypochlorite; NRPS: Non-ribosomal peptide synthase; PCR: Polymerase chain reaction; PI: Percentage of inhibition; PIG: Percent inhibition of germination; PKS: Polyketide synthase; VOC: Volatile organic compound

\section{Acknowledgements}

The authors would like to thank Dr. Alberto Uc-Varguez from CIATEJ for provide some of the fungal pathogens, Ana Lucía Tovar Álvarez from Science Faculty at Autonomous University of Querétaro, México, for their technical assistance in the SEM sample preparation and analysis.

\section{Authors' contributions}

The laboratory assays were carried out by all the authors. Data were analyzed by ZE-M and EAC-L. This study was conceived and designed by ZEM. The manuscript was written by Z-EM and EAC-L. The manuscript was revised by EG-M and ZE-M. All authors have read and approved the manuscript.

\section{Funding}

This study was supported by funds granted by Consejo Nacional de Ciencia y Tecnología (No. PN-2016-2900). L.F.P.-C. receives a bachelor grant No. 28651. E.A.C.-L. receives a postdoctoral fellowship from CONACYT 273023. The funders had no role in study design, data collection and analysis, decision to publish, or preparation of the manuscript.

\section{Availability of data and materials}

Data and materials in this study can be used as a reference by other researchers.

\section{Ethics approval and consent to participate}

Not applicable.

\section{Consent for publication}

Not applicable.

\section{Competing interests}

The authors declare that they have no competing interests.

Received: 17 June 2020 Accepted: 9 September 2020

Published online: 16 September 2020

\section{References}

Ayuso-Sacido A, Genilloud O (2005) New PCR primers for the screening of NRPS and PKS-I systems in actinomycetes: detection and distribution of these biosynthetic gene sequences in major taxonomic groups. Microb Ecol 49:1024 https://doi.org/10.1007/s00248-004-0249-6

Bognár R, Makleit S, Zsupán K, Brown BO, Lockley WJS, Toube TP, Weedon BCL (1972) Flavofungin: a mixture of 13,15,17,19,21,23,25,27-octahydroxy-31isopropyl-14-methyl- and 13,15,17,19,21,23,25,27-octahydroxy-14-methyl-31-sbutyl-hentriaconta-2,4,6,8,10,28-hexaen-31-olide. J Chem Soc Perkin Trans 1: 1848-1856 https://doi.org/10.1039/p19720001848

Bredholdt H, Galatenko OA, Engelhardt K, Fjaervik E, Terekhova LP, Zotchev SB (2007) Rare actinomycete bacteria from the shallow water sediments of the Trondheim fjord, Norway: isolation, diversity, and biological activity. Environ Microbiol 9:2756-2764 https://doi.org/10.1111/j.1462-2920.2007.01387.x

Calvo H, Mendiara I, Arias E, Gracia AP, Blanco D, Venturini ME (2020) Antifungal activity of the volatile organic compounds produced by Bacillus velezensis strains against postharvest fungal pathogens. Postharvest Biol Technol 166: 111208 https://doi.org/10.1016/j.postharvbio.2020.111208

Catão HCRM, Sales NLP, Azevedo DMQ Flavio NSS, Menezes JBC, Barbosa LV, Martinez RAS (2013) Fungicides and alternative products in the mycelial growth and germination control of Alternaria tomatophila. Idesia (Arica) 31: 21-28 https://doi.org/10.4067/S0718-34292013000300004

Challis GL, Hopwood DA (2003) Synergy and contingency as driving forces for the evolution of multiple secondary metabolite production by Streptomyces species. Proc Natl Acad Sci 100:14555-14561 https://doi.org/10.1073/pnas. 1934677100

Chen Y, Zhou D, Qi D, Gao Z, Xie J, Luo Y (2018) Growth promotion and disease suppression ability of a Streptomyces sp. CB-75 from banana rhizosphere soil. Front Microbiol 8:2704 https://doi.org/10.3389/fmicb.2017.02704

Cheng J, Yang SH, Palaniyandi SA, Han JS, Yoon TM, Kim TJ, Suh JW (2010) Azalomycin F complex is an antifungal substance produced by Streptomyces malaysiensis MJM1968 isolated from agricultural soil. J Korean Soc Appl Biol Chem 53:545-552 https://doi.org/10.3839/jksabc.2010.084

Choudhary B, Nagpure A, Gupta RK (2015) Biological control of toxigenic citrus and papaya-rotting fungi by Streptomyces violascens MT7 and its extracellular metabolites. J Basic Microbiol 55:1343-1356 https://doi.org/10.1002/jobm. 201500323

Córdova-Dávalos LE, Escobedo-Chávez KG, Evangelista-Martínez Z (2018) Inhibition of Candida albicans cell growth and biofilm formation by a bioactive extract produced by soil Streptomyces strain GCAL-25. Arch Biol Sci 70:387-396 https://doi.org/10.2298/ABS170908057C

Di Francesco A, Martini C, Mari M (2016) Biological control of postharvest diseases by microbial antagonists: how many mechanisms of action? Eur J Plant Pathol 145:711-717 https://doi.org/10.1007/s10658-016-0867-0

Evangelista-Martínez Z (2014a) Isolation and characterization of soil Streptomyces species as a potential biological control agent against fungal plant pathogens. World J Microbiol Biotechnol 30:1639-1647 https://doi.org/10. 1007/s11274-013-1568-x

Evangelista-Martínez Z (2014b) Preliminary study on some actinomycetes and evaluation of their potential antagonism against fungal pathogens. British Microbiol Res J 4:272-281 https://pdfs.semanticscholar.org/d6db/4c772 9acb0481ff236e75629e8f1cf2f47b2.pdf

Food and Agriculture Organization of the United Nations FAO (2011) Global food losses and food waste: extent, causes and prevention; FAO: Rome, Italy. http://www.fao.org/docrep/014/mb060e/mb060e00.pdf (Accessed April 2020).

González I, Ayuso-Sacido A, Anderson A, Genilloud O (2005) Actinomycetes isolated from lichens: evaluation of their diversity and detection of biosynthetic gene sequences. FEMS Microbiol Ecol 54:401-415 https://doi. org/10.1016/j.femsec.2005.05.004

Javoreková S, Kovácsová S, Medo J, Maková J, Petrová J, Hleba L, Koštálová D, Cinkocki R (2019) Soil amended with organic fertilizers as a source of actinomycetes with high potential as biocontrol agents. J Microbiol Biotechnol Food Sci 8:1352-1359 https://doi.org/10.15414/jmbfs.2019.8.6. 1352-1359

Kader AA (2005) Increasing food availability by reducing postharvest losses of fresh produce. Int Postharvest Symp Acta Hort 682:2169-2178 https://doi. org/10.17660/ActaHortic.2005.682.296

Kim YS, Lee IK, Yun BS (2015) Antagonistic effect of Streptomyces sp. BS062 against Botrytis diseases. Mycobiol 43:339-342 https://doi.org/10.5941/MYCO. 2015.43.3.339

Kim JD, Park MY, Jeon BJ, Kim BS (2019) Disease control efficacy of 32,33didehydroroflamycoin produced by Streptomyces rectiviolaceus strain DY46 against gray mold of tomato fruit. Sci Rep 9:13533 https://doi.org/10.1038/ s41598-019-49779-6

Krug JC (2004) Moist chambers for the development of fungi. In: Mueller et al (eds) Biodiversity of fungi inventory and monitoring methods. Academic Press, New York, pp 569-574

Leyronas C, Duffaud M, Nicot PC (2012) Compared efficiency of the isolation methods for Botrytis cinerea. Mycology 3:221-225 https://doi.org/10.1080/ 21501203.2012.727484

Li Q, Ning P, Zheng L, Huang J, Li G, Hsiang T (2010) Fumigant activity of volatiles of Streptomyces globisporus JK-1 against Penicillium italicum on Citrus microcarpa. Postharvest Biol Technol 58:157-165 https://doi.org/10.1016/j. postharvbio.2010.06.003

Li Q, Chen X, Jiang Y, Jiang C (2016) Morphological identification of actinobacteria. In: Dhanasekaran D, Jiang Y (eds) Actinobacteria -basics and biotechnological applications. InTech, India, pp 59-86 https://doi.org/10. $5772 / 61461$ 
Long CA, Zheng W, Deng BX (2005) Biological control of Penicillium italicum of citrus and Botrytis cinerea of grape by strain 34-9 of Kloeckera apiculata. Eur Food Res Technol 211:197-201 https://doi.org/10.1007/s00217-005-1199-z

Lyu A, Liu H, Che H, Yang L, Zhang J, Wu M, Chen W, Li G (2017) Reveromycins A and B from Streptomyces sp. 3-10: antifungal activity against plant pathogenic fungi in vitro and in a strawberry food model system. Front Microbiol 8:550 https://doi.org/10.3389/fmicb.2017.00550

Reyes-Diaz M, Lobos T, Cardemil L, Nunes-Nesi A, Retamales J, Jaakola L, Alberdi M, Ribera-Fonseca A (2016) Methyl jasmonate: an alternative for improving the quality and health properties of fresh fruits. Molecules 21:1-18 https:// doi.org/10.3390/molecules21060567

Rodríguez A, Acosta A, Rodríguez C (2014) Fungicide resistance of Botrytis cinerea in tomato greenhouses in the Canary Islands and effectiveness of nonchemical treatments against gray mold. World J Microbiol Biotechnol 30: 2397-2406 https://doi.org/10.1007/s11274-014-1665-5

Sawicka B (2019) Post-harvest losses of agricultural produce. In: Leal FW, Azul A, Brandli L, Özuyar P. Wall T (eds) Zero hunger. Encyclopedia of the UN Sustainable Development Goals. Springer, Cham https://doi.org/10.1007/9783-319-69626-3

Shafiee-Jood M, Cai X (2016) Reducing food loss and waste to enhance food security and environmental sustainability. Environ Sci Technol 50(16):84328443 https://doi.org/10.1021/acs.est.6b01993

Shirling EB, Gottlieb D (1966) Methods for characterization of Streptomyces species. Int J Syst Bacteriol 16:313-340 https://doi.org/10.1099/00207713-163-313

Shu C, Chen Q, Pi L, Zhang D, Panhwar QA, Zhou E (2017) Identification and antifungal activity analysis of two biocontrol antagonists to Colletotrichum musae. J Phytopathol 165:554-561 https://doi.org/10.1111/jph.12592

Silva MC, Polonio JC, Quecine MC, Almeida TT, Bogas AC, Pamphile JA, Pereira JO, Astolfi-Filho S, Azevedo JL (2016) Endophytic cultivable bacterial community obtained from the Paullinia cupana seed in Amazonas and Bahia regions and its antagonistic effects against Colletotrichum gloeosporioides. Microb Pathog 98:16-22 https://doi.org/10.1016/j.micpath.2016.06.023

Trejo-Estrada SR, Rivas Sl, Crawford DL (1998) In vitro and in vivo antagonism of Streptomyces violaceusniger YCED9 against fungal pathogens of turfgrass. World J Microbiol Biotechnol 14:865-872 https://doi.org/10.1023/A: 1008877224089

Tripathi P, Dubey NK (2004) Exploitation of natural products as an alternative strategy to control postharvest fungal rotting of fruit and vegetables. Postharvest Biol Technol 32:235-245 https://doi.org/10.1016/j.postharvbio. 2003.11.005

Wang C, Wang Z, Qiao X, Li Z, Li F, Chen M, Wang Y, Huang Y, Cui H (2013) Antifungal activity of volatile organic compounds from Streptomyces alboflavus TD-1. FEMS Microbiol Lett 341:45-51 https://doi.org/10.1111/15746968.12088

Wang Z, Jiang M, Chen K, Wang K, Du M, Zala'n Z, Hegyi F, Kan J (2018) Biocontrol of Penicillium digitatum on postharvest citrus fruits by Pseudomonas fluorescens. J Food Quality ID 2910481. https://doi.org/10.1155/ 2018/2910481

Weisburg WG, Barns SM, Pelletier DA, Lane DJ (1991) 16 ribosomal DNA amplification for phylogenetic study. J Bacteriol 173:697-703 https://doi.org/ 10.1128/jb.173.2.697-703.1991

Yang M, Lu L, Pang J, Hu Y, Guo Q, Li Z, Wu S, Liu H, Wang C (2019) Biocontrol activity of volatile organic compounds from Streptomyces alboflavus TD-1 against Aspergillus flavus growth and aflatoxin production. J Microbiol 57: 396-404 https://doi.org/10.1007/s12275-019-8517-9

Yuan WM, Crawford DL (1995) Characterization of Streptomyces Iydicus WYEC108 as a potential biocntrol agent against fungal root and seed rot. Appl Environ Microbial 61:3119-3128

Zhang D, Lu Y, Chen H, Wu C, Zhang H, Chen L, Chen X (2020) Antifungal peptides produced by actinomycetes and their biological activities against plant diseases. J Antibiot 73:265-282 https://doi.org/10.1038/s41429-0200287-4

\section{Publisher's Note}

Springer Nature remains neutral with regard to jurisdictional claims in published maps and institutional affiliations.

\section{Submit your manuscript to a SpringerOpen ${ }^{\circ}$ journal and benefit from:}

- Convenient online submission

- Rigorous peer review

- Open access: articles freely available online

- High visibility within the field

- Retaining the copyright to your article

Submit your next manuscript at $\boldsymbol{\nabla}$ springeropen.com 